日本原子力研究開発機構機関リポジトリ

Japan Atomic Energy Agency Institutional Repository

\begin{tabular}{|c|l|}
\hline Title & $\begin{array}{l}\text { Micro-PIXE analysis on adsorbent of extraction chromatography } \\
\text { for MA(III) recovery }\end{array}$ \\
\hline Author(s) & $\begin{array}{l}\text { Takahatake Yoko, Watanabe So, Kofuji Hirohide, Takeuchi } \\
\text { Masayuki, Nomura Kazunori, Sato Takahiro }\end{array}$ \\
\hline Citation & International Journal of PIXE, 26(3\&4), p.73-83 \\
\hline Text Version & Author's Post-print \\
\hline URL & $\underline{\text { https://jopss.jaea.go.jp/search/servlet/search?5057447 }}$ \\
\hline DOI & $\underline{\text { https://doi.org/10.1142/S0129083517500012 }}$ \\
\hline Right & $\begin{array}{l}\text { Electronic version of an article published as International Journal } \\
\text { of PIXE, Vol.26, No.3\&4, 2016, p.73-83, } \\
10.1142 / S 0129083517500012 \\
\text { CWorld Scientific Publishing Company } \\
\text { http://www.worldscientific.com/worldscinet/ijpixe }\end{array}$ \\
\hline
\end{tabular}




\title{
Micro-PIXE analysis on adsorbent of extraction chromatography for MA(III) recovery
}

\author{
Y. Takahatake, S. Watanabe, H. Kofuji, M. Takeuchi, K. Nomura \\ Japan Atomic Energy Agency, Tokai-mura, Naka-gun, Ibaraki 319-1194, Japan \\ T. Satoh \\ National Institutes for Quantum and Radiological Science and Technology \\ Takasaki, Gunma 370-1292, Japan
}

\begin{abstract}
JAEA has been conducting research and development of MA(III) recovery from HLLW by extraction chromatography technology for reduction in amount and environmental impact of radioactive waste. The behavior of adsorbed cations inside the adsorbent packed in a column is necessary to be evaluated for improvement of the adsorbent or flow-sheet to achieve targeted MA(III) recovery performance. In this paper, micro-PIXE analysis was carried out on the particles sampled from various positions of the column to reveal the behavior of cations inside the packed column with $\mathrm{CMPO} / \mathrm{SiO}_{2}-\mathrm{P}$ adsorbent using $\mathrm{RE}(\mathrm{III})$ as simulated elements of $\mathrm{MA}$ (III). Simple experiment and data analysis were shown to be effective to reveal inside of the column, and formation and transportation of the adsorption bands were observed for some cations which are extractable by the CMPO extractant. Some part of $\operatorname{Zr}(\mathrm{IV})$ and $\mathrm{Mo}(\mathrm{VI})$ were found to remain inside the column without distinct transportation even after the elution operation. Those results will contribute to design more practical MA(III) recovery flow-sheet.
\end{abstract}

Keywords: micro-PIXE analysis, reprocessing, extraction chromatography, minor actinide, CMPO

\section{Introduction}

High level liquid waste (HLLW) generated in the reprocessing of spent nuclear fuel contains many kind of radioactive nuclides. The HLLW is planned to be vitrified and geologically disposed. Minor actinides (MA(III): Am(III) and Cm(III)) contained in the HLLW are known to be long-lived and/or heat-generating nuclides, and those are desirable to be removed in order to reduce potential hazard of the vitrified radioactive waste. Japan Atomic Energy Agency (JAEA) has been conducting research and development of the extraction chromatography technology for establishing MA(III) recovery process ${ }^{1,2}$. In this technology, MA(III) is recovered from the HLLW through adsorption/elution reactions between the cations with adsorbent packed in a column. The adsorbent is prepared by impregnating an extractant into $\mathrm{SiO}_{2}-\mathrm{P}$ which is porous silica particles coated by styrenedivinylbenzene co-polymer ${ }^{3}$. Fig. 1 shows a representative scheme of MA(III) recovery flow diagram by the extraction chromatography. MA(III) and rare earth elements (RE(III)) are recovered by the $1^{\text {st }}$ column, and then MA(III) are separated from RE(III) by the $2^{\text {nd }}$ column. In our current flow-sheet, octyl(phenyl)-N,Ndiisobutylcarbamoylmethylphosphine oxide (CMPO) ${ }^{4}$ and bis(2-ethylhexyl) hydrogen phosphate (HDEHP) ${ }^{5}$ extractants are utilized in the adsorbent for the $1^{\text {st }}$ and $2^{\text {nd }}$ columns, respectively.

The previous column separation experiment showed that some improvements on the flow-sheet or structure of the adsorbents might be required to achieve our targeted MA(III) recovery ratio and decontamination factors of fission products ${ }^{6}$. Experiments using MA(III) are essential for developments in the adsorbents or in the flowsheet, however possible operations and analyses are limited due to their strong radioactivity. Therefore, fundamental characterization and screening are generally conducted under inactive environment with using simulated elements. Improvements of $\mathrm{SiO}_{2}-\mathrm{P}$ adsorbent with trial and error process require much time and frequent experiments, thus more efficient procedure is required to be developed. Simultaneous visualizations of cations inside the small silica particles and in the column during the operation would significantly contribute to identify the points to be improved. In our previous studies, micro-PIXE and X-ray absorption analyses were revealed to be powerful tools for investigating distributions of adsorbed cations inside the particle and the column, respectively ${ }^{7-9}$. Although combination of those two experimental techniques is effective, those analyses have to be carried out in different facilities with limited available time. Single experiment and simple data analysis are required for the practical use in evaluation of the extraction chromatography adsorbent and process. In this study, the behavior of cations inside the $\mathrm{CMPO} / \mathrm{SiO}_{2}-\mathrm{P}$ particle during the column operation was tried to be investigated only by micro-PIXE analysis to establish simple evaluation method for the extraction chromatography process. 


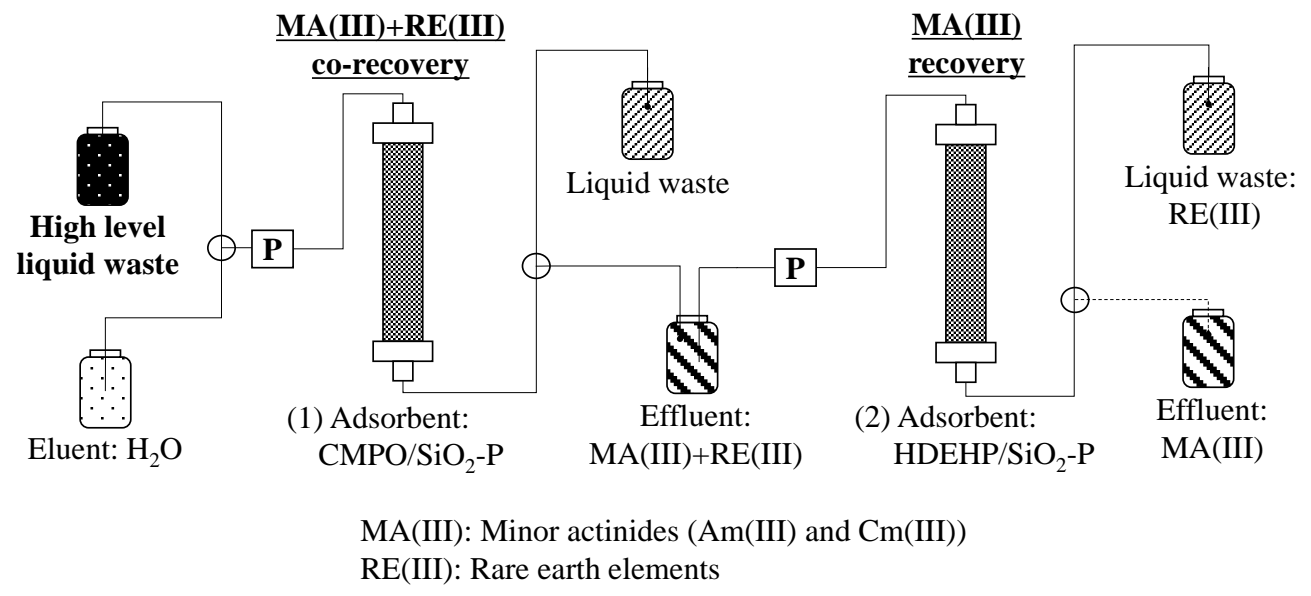

Fig. 1. A representative scheme of MA(III) recovery flow diagram and the adsorbents utilizing our current flow-sheet.

\section{Materials and Methods}

Average diameter and pore size of $\mathrm{SiO}_{2}-\mathrm{P}$ used in this study were $50 \mu \mathrm{m}$ and $50 \mathrm{~nm}$, respectively. Impregnation of $\mathrm{CMPO}$ (Fig. 2) into $\mathrm{SiO}_{2}-\mathrm{P}$ was carried out according to the article ${ }^{3}$. $\quad \mathrm{CMPO} / \mathrm{SiO}_{2}-\mathrm{P}$ was packed in the glass column of $1 \mathrm{cmID}$ and $32.5 \mathrm{cmH}$. After supplying excess amount of simulated HLLW against adsorption capacity of the column, deionized water was supplied as an eluent. The effluent was fractionally collected at every 1 bed volume (BV; $\left.25.5 \mathrm{~cm}^{3}\right)$. Concentrations of cations in the feed solution and the fractions were determined by ICP-AES analysis. Composition of the simulated HLLW is shown in Table 1, where Eu(III) is simulated element for MA(III). After the adsorption operation or the adsorption/elution operation, the $\mathrm{CMPO} / \mathrm{SiO}_{2}-\mathrm{P}$ were sampled at every $5 \mathrm{~cm}$ from the top of the column, and then dried at $60^{\circ} \mathrm{C}$ in atmospheric environment. Those particles were supplied to the micro-PIXE analysis.

The micro-PIXE analysis was held on the single-ended accelerator at Takasaki Advanced Radiation Research Institute. Proton beams accelerated up to $3 \mathrm{MeV}$ were transported to a microbeam formation system. The beams were focused to a spot approximately $1 \times 1 \mu \mathrm{m}^{2}$ on particles of $\mathrm{CMPO} / \mathrm{SiO}_{2}-\mathrm{P}$. Average beam current was $100 \mathrm{pA}$, and the scanning size was set at $100 \times 100 \mu^{2}$. Characteristic X-rays from the target were detected by a $\mathrm{Si}(\mathrm{Li})$ detector with a 100- $\mu \mathrm{m}$-thick fanny filter having a 3-mm diameter pinhole for preventing recoiled protons.

Extended X-ray Absorption spectra of some sample particles were collected at BL27B beamline of Photon Factory of High Energy Accelerator Research Organization (KEK), Japan, to support a discussion.

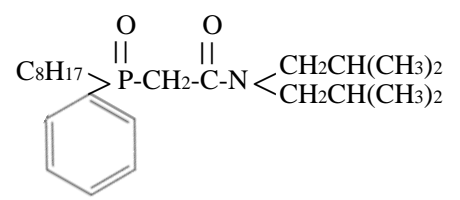

Fig. 2. Chemical structure of CMPO.

Table 1. Composition of the feed solution through the column that simulated HLLW. The solution was prepared by nonradioactive nuclides.

\begin{tabular}{cccccccccccccc}
\hline \hline Component & $\mathrm{Ba}$ & $\mathrm{Sr}$ & $\mathrm{Zr}$ & $\mathrm{Ru}$ & $\mathrm{Y}$ & $\mathrm{La}$ & $\mathrm{Ce}$ & $\mathrm{Nd}$ & $\mathrm{Sm}$ & $\mathrm{Eu}$ & $\mathrm{Mo}$ & $\mathrm{Pd}$ & $\mathrm{H}^{+}$ \\
\hline $\begin{array}{c}\text { Concentration } \\
{[\mathrm{mmol} / \mathrm{L}]}\end{array}$ & 7.8 & 7.3 & 17 & 14 & 3.5 & 6.4 & 48 & 21 & 4.7 & 0.64 & 9.2 & 7.0 & 4000 \\
\hline
\end{tabular}



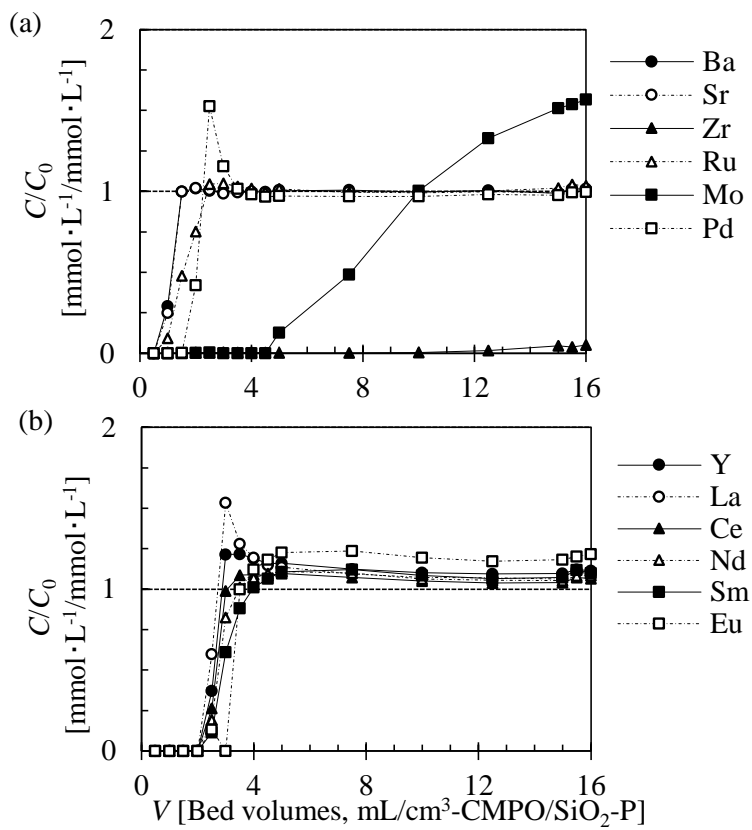

Fig. 3. Breakthrough curves of cations in the simulated HLLW for the $\mathrm{CMPO} / \mathrm{SiO}_{2}-\mathrm{P}$ packed column. Results are separately shown in two figures (a) and (b) for easy to being understood. (a) Ba, Sr, Zr, Ru, Mo and Pd. (b) Y, La, Ce, Nd, Sm and Eu. $\quad C_{0}$ is concentration of the cations in the feed solution, $C$ is concentration of that in a fraction of effluent. $V$ is flow volume of solutions. After the operation, $\mathrm{CMPO} / \mathrm{SiO}_{2}-\mathrm{P}$ were sampled at every $5 \mathrm{~cm}$ from the top of the column.

\section{Results and discussion}

Breakthrough curves of cations in the simulated HLLW for the $\mathrm{CMPO} / \mathrm{SiO}_{2}-\mathrm{P}$ packed column are shown in Fig. 3, here $C$ and $C_{0}$ correspond to concentrations of cations in the effluent and the feed solution, respectively. When $C / C_{0}$ increased up to 1 , adsorption of the $\mathrm{CMPO} / \mathrm{SiO}_{2}-\mathrm{P}$ column reached at equilibrium. The value of $C / C_{0}$ above 1 must be elution of elements from $\mathrm{CMPO} / \mathrm{SiO}_{2}-\mathrm{P}$ as a result of competitive adsorption of cations. $\mathrm{Ba}(\mathrm{II}), \mathrm{Sr}(\mathrm{II})$ and $\mathrm{Ru}(\mathrm{III})$ were not adsorbed by $\mathrm{CMPO} / \mathrm{SiO}_{2}-\mathrm{P}$, and these results reasonably agree with the previous report ${ }^{2}$. $\quad \mathrm{RE}(\mathrm{III})-\mathrm{Y}(\mathrm{III}), \mathrm{La}(\mathrm{III}), \mathrm{Ce}(\mathrm{III}), \mathrm{Nd}(\mathrm{III}), \mathrm{Sm}(\mathrm{III})$ and $\mathrm{Eu}(\mathrm{III})-$ were adsorbed by the column, and they showed breakthrough at $V=2 \mathrm{BV}$, where breakthrough of this paper means $5 \%$ breakthrough. While larger amount of $\mathrm{Zr}(\mathrm{IV})$ and $\mathrm{Mo}(\mathrm{VI})$ were adsorbed than $\mathrm{RE}(\mathrm{III})$, and they finally show their breakthrough at $V=4$ and 15 for $\mathrm{Mo}(\mathrm{VI})$ and $\mathrm{Zr}(\mathrm{IV})$, respectively. The adsorbed $\mathrm{RE}(\mathrm{III})$ were gradually discharged from the column with progress in adsorption of $\mathrm{Zr}(\mathrm{IV})$ and $\mathrm{Mo}(\mathrm{VI})$. These results suggest that $\mathrm{Zr}(\mathrm{IV})$ and $\mathrm{Mo}(\mathrm{VI})$ are preferentially adsorbed by the $\mathrm{CMPO} / \mathrm{SiO}_{2}-\mathrm{P}$. As $\mathrm{MA}(\mathrm{III})$ behave like $\mathrm{RE}(\mathrm{III})$ in the $\mathrm{CMPO} / \mathrm{SiO}_{2}-\mathrm{P}$ column, concentrations of $\mathrm{Zr}(\mathrm{IV})$ and $\mathrm{Mo}(\mathrm{VI})$ in the HLLW would significantly influence on throughput and performance of the MA(III) recovery process. More detail transportation behavior of RE(III), $\mathrm{Zr}(\mathrm{IV})$ and $\mathrm{Mo}(\mathrm{VI})$ in the column are necessary to be comprehended in order to design an optimized flow-sheet with the largest throughput and efficiency.

Characteristic X-ray spectra of the $\mathrm{CMPO} / \mathrm{SiO}_{2}-\mathrm{P}$ particle sampled from the column at $Z=0-5$ (upper part), 15-20 (middle part) and 30-32.5 (bottom part) cm after the adsorption operation are shown in Fig. $4 . \quad$ Peaks of Si and $\mathrm{P}$ were originated from porous silica particle and CMPO, respectively, and those of other elements were attributed to the adsorbed elements. Amount of RE(III) are seemed to increase with coming down from the inlet to the outlet of the column, which must be reasonably explained by transportation of RE(III) caused by occupation of the adsorption sites with $\mathrm{Zr}(\mathrm{IV})$ and $\mathrm{Mo}(\mathrm{VI})$.

Table 2 shows density of $\mathrm{RE}(\mathrm{III})$ in the $\mathrm{CMPO} / \mathrm{SiO}_{2}-\mathrm{P}$ calculated by X-ray absorption spectra of the sampled adsorbent from middle part of the column with the mass absorption coefficients of the corresponding elements ${ }^{10}$. 
Table 2. Density of elements in the $\mathrm{CMPO} / \mathrm{SiO}_{2}-\mathrm{P}$ at middle part of the column after the adsorption operation.

\begin{tabular}{cc}
\hline \hline Element & Density of element $\left[\mathrm{g} / \mathrm{cm}^{3}\right]$ \\
\hline \hline $\mathrm{Y}$ & $3.2 \times 10^{-4}$ \\
\hline $\mathrm{La}$ & $2.1 \times 10^{-4}$ \\
\hline $\mathrm{Ce}$ & $4.7 \times 10^{-3}$ \\
\hline $\mathrm{Nd}$ & $5.1 \times 10^{-3}$ \\
\hline $\mathrm{Sm}$ & $2.3 \times 10^{-3}$ \\
\hline $\mathrm{Eu}$ & $1.7 \times 10^{-4}$ \\
\hline $\mathrm{Pr}$ & $4.6 \times 10^{-4}$ \\
\hline \hline
\end{tabular}

Relative concentration

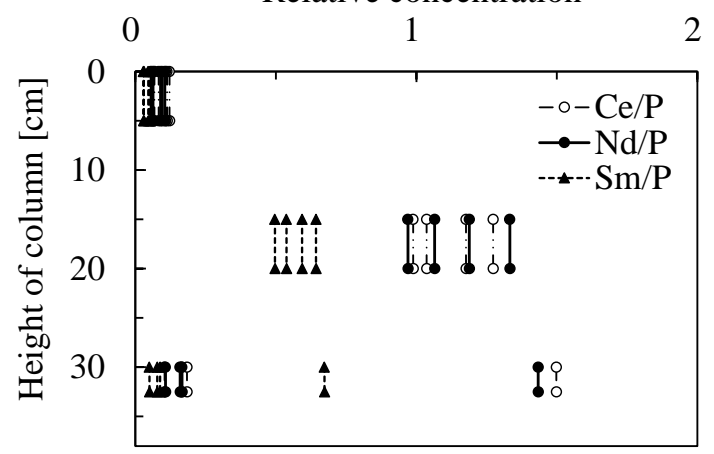

Fig. 5. Variation of relative concentration of Ce, $\mathrm{Nd}$ and Sm to $\mathrm{P}$ with height of the column after the adsorption operation.

Seven RE(III) were found in $\mathrm{CMPO} / \mathrm{SiO}_{2}-\mathrm{P}$ where $\operatorname{Pr}(\mathrm{III})$ might be impurities in regents of other RE(III), and three high density elements-Ce(III), Nd(III) and Sm(III)- were identified in spectra obtained by micro-PIXE analysis, shown in Fig. 4.

Peak intensities of Ce(III), Nd(III) and Sm(III) in a spectrum cannot be directly compared with those in other spectra due to differences in 1) the dose rate for the analysis, 2) shape and size of the particles and 3) the concentration of the CMPO extractant in the particles. Normalization of intensities of peaks for Ce(III), Nd(III) and Sm(III) is necessary for the comparison. RE(III) form complex with CMPO according to the equation (1), and the normalization can be achieved by dividing intensities of $\mathrm{Ce}(\mathrm{III}), \mathrm{Nd}(\mathrm{III})$ and $\mathrm{Sm}(\mathrm{III})$ by that of $\mathrm{P}$ (referred to "Ratios of peak intensities").

$$
\mathrm{RE}^{3+}+3 \mathrm{NO}_{3}^{-}+n \mathrm{CMPO} \rightarrow \mathrm{RE}\left(\mathrm{NO}_{3}\right)_{3} \cdot(\mathrm{CMPO})_{\mathrm{n}},(n=2 \text { or } 3)
$$

Those data gives information of relative concentrations of adsorbing RE(III) on the particle normalized with concentration of CMPO, and influence of such as particle shape and size on the concentrations should be canceled. Ratios of peak intensities of Ce(III), Nd(III) and Sm(III) to that of P are shown in Fig. 5 . Four or five particles on each part were analyzed, and the results about all analyzed particles are shown. Most relative concentration profiles showed the maximum of the ratios of peak intensities at $15-20 \mathrm{~cm}$, and the maximum is considered to be the adsorption bands of RE(III). On one particle at the bottom part of the column, three relative concentrations showed high value, and which reasonably agree with the elution of RE(III) resulted from the competitive adsorption of cations. Consequently, we could conclude that simple data treatment of the micro-PIXE analysis on the adsorbent sampled from the column has potential to reveal the transport of cations inside the packed column.

Fig. 6 shows the characteristic X-ray spectra of particles sampled after the adsorption/elution operation. The peaks of $\mathrm{Ce}(\mathrm{III}), \mathrm{Nd}(\mathrm{III})$ and $\mathrm{Sm}(\mathrm{III})$ were not observed. So Ce(III), Nd(III) and Sm(III) were discharged by the elution operation. 


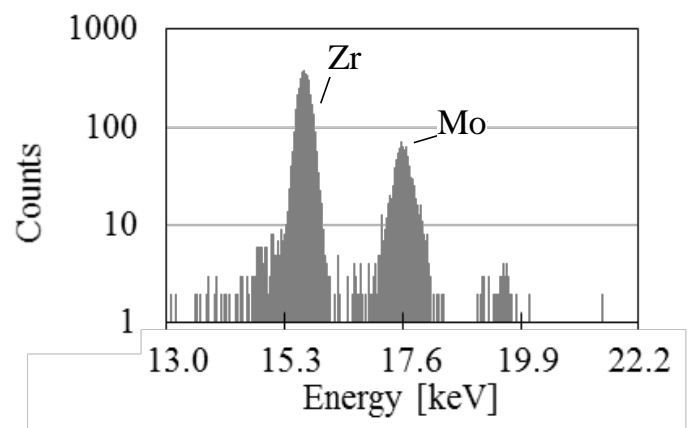

Fig. 7. X-ray spectrum of the $\mathrm{CMPO} / \mathrm{SiO}_{2}-\mathrm{P}$ particle sampled at upper part of the column $(0-5 \mathrm{~cm}$ from the top) after the adsorption operation obtained by micro-PIXE analysis. The particle was same as that showed analysis result in Fig. 4 (a).

(a) After the adsorption operation

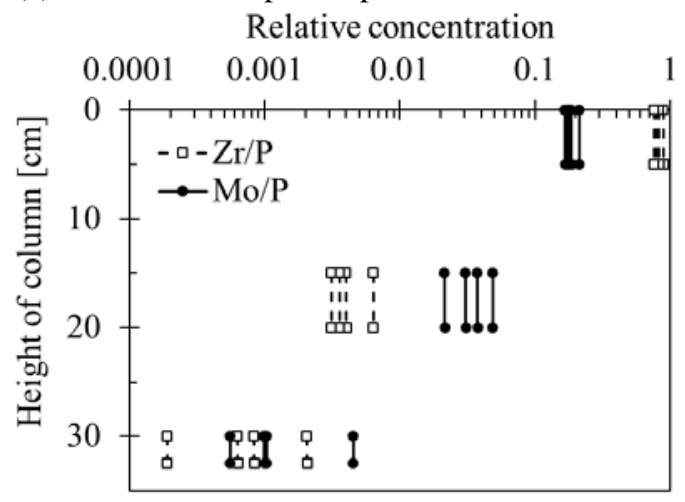

(b) After the adsorption/elution operation

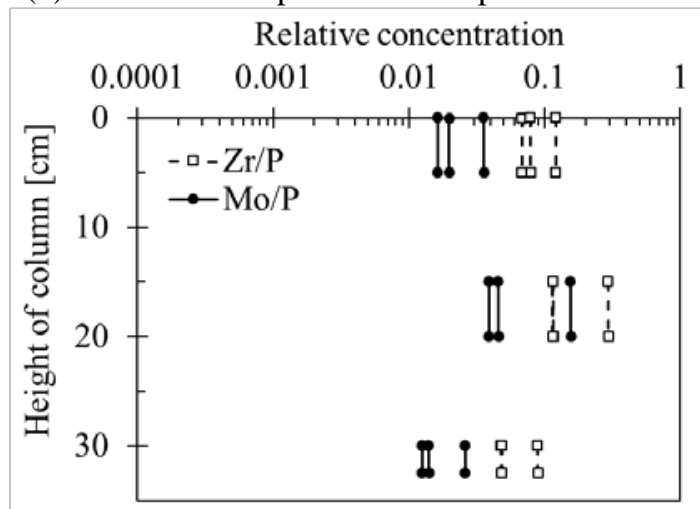

Fig. 8. Ratios of peak intensities of $\mathrm{Zr}(\mathrm{IV})$ and $\mathrm{Mo}(\mathrm{VI})$ to $\mathrm{P}$ on the $\mathrm{CMPO} / \mathrm{SiO}_{2}-\mathrm{P}$ particles with height of column. (a) After the adsorption operation, (b) After the adsorption/elution operation. Relative concentration of $\mathrm{Zr} / \mathrm{P}$ and $\mathrm{Mo} / \mathrm{P}$ on original particles are under about 0.001 .
Fig. 7 shows X-ray spectrum obtained by the PIXE analysis on the $\mathrm{CMPO} / \mathrm{SiO}_{2}-\mathrm{P}$ particle sampled from upper part of the column after the adsorption operation, here the characteristic lines of $\mathrm{Zr}(\mathrm{IV})$ and $\mathrm{Mo}(\mathrm{VI})$ were observed. Breakthrough curves shown in Fig. 3 suggest that $\mathrm{Zr}(\mathrm{IV})$ and $\mathrm{Mo}(\mathrm{VI})$ were preferentially adsorbed by the $\mathrm{CMPO} / \mathrm{SiO}_{2}-\mathrm{P}$, and this feature agrees with the X-ray profile.

Ratios of peak intensities of $\mathrm{Zr}(\mathrm{IV})$ and $\mathrm{Mo}(\mathrm{VI})$ to that of $\mathrm{P}$ are shown in Fig. 8. Just after the adsorption operation, those took the maximums at upper part of the column and adsorption of $\mathrm{Zr}(\mathrm{IV})$ and $\mathrm{Mo}(\mathrm{VI})$ at bottom part were almost negligible. Mo/P was larger than $\mathrm{Zr} / \mathrm{P}$ at middle part, thus some part of $\mathrm{Mo}(\mathrm{VI})$ must be transferred to downward as a result of adsorption competition with $\mathrm{Zr}(\mathrm{IV})$ regarding the breakthrough behavior of them. Even after supplying the eluent into the column, both $\mathrm{Zr}(\mathrm{IV})$ and $\mathrm{Mo}(\mathrm{VI})$ remained inside the column though their adsorption bands seemed to move to downstream of the column. $\mathrm{Zr}(\mathrm{IV})$ and $\mathrm{Mo}(\mathrm{VI})$ are selectively extracted by CMPO and hardly eluted by water, and this characteristics can reasonably explain the previous experimental data ${ }^{2}$. The adsorbed $\mathrm{Zr}(\mathrm{IV})$ and Mo(VI) have to be washed out by an appropriate wash solution before the end of operation, because the remaining $\mathrm{Zr}(\mathrm{IV})$ and $\mathrm{Mo}(\mathrm{VI})$ in $\mathrm{CMPO} / \mathrm{SiO}_{2}-\mathrm{P}$ suppress adsorption of $\mathrm{MA}(\mathrm{III})$ as well as RE(III) in case of reuse of the column. X-ray absorption of the particle surely showed the existence of $\mathrm{Zr}$, and EXAFS analysis on the spectrum with WinXAS $2.3^{11}$ and FEFF8.0 ${ }^{12}$ suggests that $\mathrm{Zr}(\mathrm{OH})_{4}$ forms complex with CMPO inside the particle. Backextraction of $\mathrm{Zr}(\mathrm{OH})_{4}$ from the complex with $\mathrm{CMPO}$ has to be established for the practical use of the technology. Decontamination of $\mathrm{Zr}(\mathrm{IV})$ and $\mathrm{Mo}(\mathrm{VI})$ in advance with MA(III) recovery process is also effective. Our previous experiments showed that $\mathrm{HDEHP} / \mathrm{SiO}_{2}-\mathrm{P}$ is applicable to selectively removing $\mathrm{Zr}(\mathrm{IV})$ and $\mathrm{Mo}(\mathrm{VI})$ from acidic solution, although elution of $\mathrm{Zr}(\mathrm{IV})$ from the adsorbent is still difficult ${ }^{13}$. An appropriate procedure or process will be employed in the near future based on fundamental studies.

\section{Conclusion}

The behavior of cations inside the $\mathrm{CMPO} / \mathrm{SiO}_{2}-\mathrm{P}$ particle during the column operation were discussed only by micro-PIXE analysis for simple evaluation of the extraction chromatography process. The adsorption bands of RE(III) which behaves like MA(III) were suggested by considering about relative concentrations. Some part of $\mathrm{Zr}(\mathrm{IV})$ and $\mathrm{Mo}(\mathrm{VI})$ was found to remain inside the column without distinct transportation even after the elution operation. So,
(III) recovery process, and back-extraction operation of the specie has to be considered for the practical use of MA(III) recovery process, and
decontamination of $\mathrm{Zr}(\mathrm{IV})$ and $\mathrm{Mo}(\mathrm{VI})$ in advance with MA(III) recovery process is also effective when reusing the column. Simple experiment and data analysis of micro-PIXE were shown to be effective to reveal inside the column, and those results will contribute to design more practical MA(III) recovery flow-sheet. 


\section{Acknowledgement}

Part of this work was financed by Agency for Natural Resources and Energy, the Ministry of Economy, Trade and Industry of Japan (METI) under the framework of "Basic Research Programs for the Next Generation Vitrification Technology”. X-ray absorption experiments were carried out under the proposal of $2016 \mathrm{G} 557$ of the Photon Factory, KEK. The authors would like to thank staffs of the Takasaki Ion Accelerators for Advanced Radiation Application (TIARA) for micro-PIXE analysis, and helpful discussions.

\section{References}

1. S. Watanabe, I. Goto, K. Nomura, Y. Sano, Y. Koma, Extraction Chromatography Experiments on Repeated Operation Using Engineering Scale Column System, Energy Procedia, 7, 449-453 (2011).

2. S. Watanabe, T. Senzaki, A. Shibata, K. Nomura, Y. Koma, Y. Nakajima, MA recovery experiments from genuine HLLW by extraction chromatography, Proceedings of Global 2011, Makuhari, Japan, December 1116, 2011, Paper 387433, CD-ROM (2011)

3. Y.-Z. Wei, K.N. Sabharwal, M. Kumagai, T. Asakura, G. Uchiyama, S. Fujine, Studies on the separation of minor actinides from high-level wastes by extraction chromatography using novel silica-based extraction resins, Nucl. Technol. 132, 3, 413-423 (2000)

4. E. P. Horwitz, D. G. Kalina, H. Diamond, G. F. Vandegrift, W. W. Schulz, The TRUEX Process - A Process for the Extraction of the Transuranic Elements from Nitric Acid Wastes Utilizing Modified PUREX Solvent, Solvent Extraction and Ion Exchange, 3(1\&2), 75-109 (1985)

5. B. Weaver, F. A. Kappelmann, TALSPEAK: A New Method of Separating Americium and Curium from the Lanthanides by Extraction from an Aqueous Solution of an Aminopolyacetic Acid Complex with a Monoacidic Organophosphate or Phosphonate, ORNL-3559 (1964)

6. S. Watanabe, K. Nomura, S. Kitawaki, A. Shibata, H. Kofuji, Y. Sano, M. Takeuchi, Flow-sheet study of MA recovery by extraction chromatography for SmART cycle project, Procedia Chemistry, 21, 101-108 (2016)

7. T. Satoh, A. Yokoyama, A. Kitamura, T. Ohkubo, Y. Ishii, Y. Takahatake, S. Watanabe, Y. Koma, W. Kada, Particle induced X-ray emission-computed tomography analysis of an adsorbent for extraction chromatography, Nuclear Instruments and Methods in Physics Research B 371, 419-423 (2016)

8. S. Watanabe, Y. Sano, M. Myouchin, Y. Okamoto, H. Shiwaku, A. Ikeda-Ohno, S. Suzuki, T. Yaita, In-Situ Analysis of Chemical State and Ionic Distribution in the Extraction Chromatography Column, J. Ion Exchange, 21, 3, 189-194 (2010)

9. S. Watanabe, Y. Sano, H. Shiwaku, T. Yaita, S. Ohno, T. Arai, H. Matsuura, M. Koka, T. Satoh, Local structure and distribution of remaining elements inside extraction chromatography adsorbents, Nuclear Instruments and Methods in Physics Research B (in press)

10. J. H. Hubbell, S. M. Seltzer, Table of X-Ray Mass Attenuation Coefficients and Mass Energy-Absorption Coefficients from $1 \mathrm{keV}$ to $20 \mathrm{MeV}$ for Elements $\mathrm{Z}=1$ to 92 and 48 Additional Substances of Dosimetric Interest, https://www.nist.gov/pml/x-ray-mass-attenuation-coefficients, NIST PHYSICAL MEASUREMNT LBORATORY, NIST Standard Reference Database 126, May 1996 Release

11. T.Ressler, WinXAS; a Program for X-ray Absorption Spectroscopy Data Analysis under MS-Windows, J. Synchrotron Rad. 5, 118-122 (1998)

12. S. I. Zabinsky, J. J. Rehr, A. Aukudinov, R. C. Albers, M. J. Eller, FEFF8.0; Multiple-scattering calculations of X-ray-absorption spectra, Phys. Rev. B52, 2995 (1995)

13. R. Abe, K. Nagoshi, T. Arai, S. Watanabe, Y. Sano, H. Matsuura, H. Takagi, N. Shimizu, M. Koka, T. Satoh, Microscopic analyses of complexes fromed in adsorbent for Mo and Zr separation chromatography, Nuclear Instruments and Methods in Physics Research B (in press) 